\title{
Restricting private-sector practice using contracts
}

\section{Colleen M. Flood LLM SJD, Pauline Allen PhD, Bryan Thomas MA SJD, Kathryn Walker PhD}

$\mathrm{F}$ ew debates are more polarizing in Canada than whether physicians should be allowed to bill private patients for medically necessary care. Building on the precedent in the Chaoulli case, ${ }^{1}$ there are several constitutional challenges pending that seek to strike down provincial laws banning extra-billing and dual practice (whereby doctors bill the public payer but can also bill privately). ${ }^{2}$ If these claims succeed, how will provincial governments respond? In this article, we discuss one option, drawn from Western Europe: instead of a ban, governments could address the issue contractually.

\section{Why regulate extra-billing and dual practice?}

With respect to extra-billing, the obvious concern is that physicians will price services out of reach for many in need of care. ${ }^{3}$

With respect to dual practice, there is concern that physicians will prioritize private-sector patients, which will exacerbate wait times in the public sector - a problem that has been observed in Australia's two-tier system. ${ }^{4}$ Dual practice may also affect the quality of care in the public system, because the lure of the private sector will be greatest for highly qualified physicians whose services command high prices. A compounding worry is that physicians in dual practice will "cream-skim" patients with simpler medical conditions for their private practice, leaving those with complicated conditions to the public system (and more junior physicians).

Finally, conflicts of interest may arise, with physicians in dual practice incentivized to encourage or exaggerate wait times in the public stream, to drive up demand for private care. These concerns materialized in Manitoba in the 1990s, when dual practice was allowed for cataract surgery. Public-stream patients of dualpractice physicians faced wait times up to 13 weeks longer than patients of physicians practising only in the public sector..$^{5}$ A 1994 study of Alberta's experience with physicians splitting their time performing cataract surgery between public hospitals and private clinics - charging facility fees (a form of extra-billing) in the latter - reached similar findings. ${ }^{6}$

On the other side of the ledger is evidence that governments have not been sufficiently proactive in addressing wait times. ${ }^{7}$ Moreover, some of the concerns that we have outlined assume a limited supply of physician resources; recently, there appears to be a surplus in some specialties and locations. ${ }^{8}$ It is difficult to predict how courts will interpret this mixed evidence; however, provinces are well advised to prepare contingency plans in the event that current laws restricting dual practice and extra-billing are overturned.

\section{Why physician contracts rather than direct regulation?}

Current constitutional challenges in Ontario, Alberta and British Columbia build upon the precedent of the Supreme Court's decision in the Chaoulli case, which attacked Quebec's law banning private health insurance. To date, the Chaoulli decision has not been as disruptive to Quebec's single-payer system as some feared. This is due largely to the province's calibrated legislative response, which liberalized private insurance for medically necessary care, but only for select services singled out in the ruling (i.e., total hip or knee replacement and major cataract surgery); meanwhile, access to these services within the public system was shored up with wait-time guarantees. ${ }^{9}$ The current set of constitutional challenges is more expansive, targeting restrictions on extra-billing, dual practice and

\section{- KeY POINTS}

- Several Western European countries limit two-tier care by negotiating contractual restrictions with physicians to limit their private-sector activity.

- Contract-based approaches to regulating two-tier care range from strict exclusivity clauses to limits on hours or earnings in the private sector.

- In the event that constitutional challenges to existing laws succeed, Canadian policy-makers should explore the use of physician contracts as a fallback strategy for limiting two-tier care.

- Physicians should be aware that governments may respond to successful constitutional challenges with policy measures, like contracts, that could be more restrictive of physician autonomy than current laws. 
user charges, which means that Quebec's targeted approach may not be feasible. How then can provincial governments respond?

One option, common in Western Europe but little discussed in the Canadian context, is to address extra-billing and dual practice through government contracts with physicians. Such contracts could stipulate the time physicians must devote to public patients or, alternatively, limit the time that physicians practise privately. We summarize these contractual approaches.

\section{Restrictive approaches}

One option is an exclusivity clause that contractually forbids private billing by physicians working in the public sector. A concern with this option is that specialist physicians will opt out of the public system altogether or relocate to provinces with more permissive contracts (if such exist). Exclusive public contracts prompted an exodus of senior physicians from the public sector to the private sector in Greece, for example. ${ }^{10}$ In Canada, however, we do not see a substantial number of physicians opting out of Medicare under the existing statutory ban on dual practice; indeed, there is currently a buyer's market for physician services. ${ }^{8}$ Opting out might become more attractive, though, if the courts also overturn laws restricting duplicative private insurance.

Short of demanding exclusivity, provinces might contractually limit private practice income $^{11}$ - an approach taken by the United Kingdom until recently. ${ }^{12}$ As with exclusivity clauses, income limits may prompt some physicians, particularly senior physicians whose services command higher prices, to opt out of the public system altogether or to relocate. There is also evidence of enforcement problems with income limits: data from the UK show that its $10 \%$ income cap was routinely violated until it was dropped from contract renewals in 2003. It is unclear whether the violations were due simply to lax enforcement; on its face, compliance could be monitored by auditing physicians' tax returns. ${ }^{13}$

Another option is to contractually limit the time physicians devote to private practice. Ireland prohibits public-sector physicians from devoting more than $20 \%$ of their clinical workload to private-pay patients. An advantage here is that time limits impose no hard cap on income earned in the private sector - dual practice specialists can earn whatever the market will bear for their services, within the time limit. There may be enforcement issues here, too, with Ireland's Auditor General reporting that the country's $20 \%$ time limit is regularly violated. ${ }^{14}$

To this point we have assumed a single, uni- form contract for all physicians, whether specialist or general practitioner, senior or junior. Yet some jurisdictions (e.g., Ireland, the UK and France) use contracts to restrict dual practice only for recently qualified or newly immigrated physicians. ${ }^{3}$ As with options already discussed, this tiered approach may affect quality of care in the public stream.

\section{Incentive-based approaches}

Some jurisdictions have used contractual incentives, rather than restrictions, to secure physician loyalty to their public systems. For example, the Spanish government offers salary supplements to physicians who sign restrictive contracts. ${ }^{15} \mathrm{In}$ Portugal, there are four categories of contract, and remuneration rises with increased time commitment to the public system. ${ }^{16}$ In Italy, only physicians who sign exclusive public contracts are eligible for promotion. ${ }^{17}$

Incentive-based approaches are touted as fostering public service values ${ }^{18}$ and may appear less draconian than restrictive approaches. Where market demand creates a substantial disparity between public and private remunerations, attempts to buy loyalty to the public system may be very costly if they are to succeed. Incentivebased approaches may also be difficult to negotiate, as seen in 2003 contract negotiations in the UK, where physician opposition blocked the introduction of an incentive for commitment to the National Health Service. ${ }^{19}$

\section{Administrative approaches}

In some jurisdictions (e.g., Ireland, France, Italy, Austria and Germany), dual-practice physicians are allowed to see private patients in public hospitals, in the hope that decreased travel time will limit distraction from public-sector work. It is believed that monitoring dual practice is more easily achieved within public hospitals, which complements other regulatory measures such as limitations on private-sector time..$^{18}$ Ireland has tested this approach with mixed results: despite allowing private practice in public hospitals, the country has struggled to enforce its $20 \%$ limit on care delivered to private-pay patients. ${ }^{14}$ There are also ethical concerns around allowing privatized care in public hospitals, particularly given Canada's high occupancy levels.

\section{Codes of ethics}

Professional regulatory bodies may play a role in limiting dual practice through their codes of ethics. In the UK, the physicians' code of conduct includes, for example, rules of disclosure vis-à-vis conflicts of interest. ${ }^{3}$ Similarly, the Royal Dutch Medical Association's code of ethics stipulates 
that all patients be treated equally, regardless of ability to pay. ${ }^{3}$ The Canadian Medical Association's code of ethics does not address dual practice, but it does address conflicts of interest (in articles 7, 11 and 49), discourages "cream skimming" of patients (article 17) and calls upon physicians to "promote equitable access to health care resources" (article 43). ${ }^{20}$ Professional regulatory bodies could conceivably address dual practice by establishing stronger mechanisms for compliance with these requirements.

\section{How should contractual restrictions be calibrated in the Canadian context?}

If court challenges succeed in liberalizing dual practice and extra-billing in Canada, there may be a swift demand for privatized care, owing to the already strong penetration of private insurance. Sixty-five percent of Canadians have private health insurance. Although the coverage is primarily for prescription drugs, dental services and eye care, the proportion is much higher than, for example, the $11 \%$ of the UK population who have private health insurance. ${ }^{21}$ Thus, we need to use Canadian data to model the consequences of further liberalization of laws restricting private practice.

Furthermore, the feasibility of using other jurisdictions' contractual approaches in Canada depends on various country-specific factors. For example, limits on income or time devoted to private-sector work are more readily implemented in the UK, where physicians are paid on a salaried basis and are subject to greater managerial control of the nature of their work and their time by government agencies. Monitoring and enforcement might be more challenging in Canada, where physicians generally operate as independent contractors, billing public insurers on a fee-for-service basis. The prospect of shifting to contracts as a modality of regulation may bring a rethinking of Canada's attachment to feefor-service billing, which now accounts for $70 \%$ of clinical payments to physicians, ${ }^{22}$ and hasten the move toward alternative reimbursement plans. The quid pro quo might be that, in exchange for the freedom to engage in dual practice, most if not all physicians will shift to salary arrangements subject to stronger oversight when working in the public sector. We also need to consider to what extent attempts to regulate by contractual means will draw protests, notably from physicians. In the UK, plans for a sevenyear exclusivity rule for newly certified consultants were scuttled amid opposition from phys- icians. ${ }^{23}$ Physicians in Canada successfully resisted the statutory prohibition on extra-billing for nearly two decades before the Canada Health Act was enacted. ${ }^{9}$

To assess the potential of physician contracts in Canada, we also need to explore whether such an approach itself would survive constitutional challenges of the sort now being levelled against statutory restrictions. Although restrictive contracts for physicians may have comparable effects (i.e., limiting patients' ability to purchase care privately), there are key differences. For example, restrictive contracts, being the outcome of labour negotiations, are arguably a less direct form of government regulation. Plaintiffs may have difficulty establishing that government contracts caused their inability to access privately financed care - a crucial evidentiary burden on which a Chaoulli-type claim recently foundered in Alberta courts. ${ }^{24}$

\section{What are the potential consequences of challenging restrictions on dual practice?}

Physicians backing the ongoing constitutional challenges envision a scenario, it seems, wherein Canada's health care system is organized just as it is today, minus the statutory restrictions on dual practice and extra-billing. In making their case, they point to the fact that many Western European countries manage to sustain universal public health care without such regulations. ${ }^{1}$ If Canadian governments are led down this path through court challenges, they should respond by asking what other measures the European countries have taken to protect access and equity. The diverse contract-based strategies we have outlined represent only a small part of what might be achieved through contracts, however. England, for example, has used National Health Service contracts to demand improvements from physicians in terms of quality and efficiency of care. ${ }^{25}$

Canadians resoundingly support equitable access to high-quality health care, yet the debate over two-tier care is often framed as a binary choice between preserving or dismantling the status quo. As we have seen, there is a wealth of other options for restricting private-sector care. Governments should explore their options. For their part, physicians should appreciate that current restrictions on private practice are part of a larger entente with government that affords them considerable professional autonomy. A shakeup by the courts may lead governments to pursue other, potentially more intrusive, regulatory approaches. 


\section{References}

1. Chaoulli v. Quebec (Attorney General), 2005 SCC 35 at para 75.

2. Canadian Independent Medical Clinics Association, Cambie Surgeries Corporation, Delbrook Surgical Center Inc., et al. v. Medical Services Commission of British Columbia, Minister of Health Services of British Columbia, Attorney General of British Columbia. (Jan. 28, 2009) (Writ of Summons). Available: http://medicare.ca/wp-content/uploads/2009/05/cimcawrit.pdf (accessed 2014 Dec. 3).

3. Flood CM, Haugan A. Is Canada odd? A comparison of European and Canadian approaches to choice and regulation of the public/ private divide in health care. Health Econ Policy Law 2010;5: 319-41.

4. Duckett SJ. Living in the parallel universe in Australia: public medicare and private hospitals. CMAJ 2005;173:745-7.

5. DeCoster C, Carrière KC, Peterson S, et al. Surgical waiting times in Manitoba. Winnipeg: Manitoba Centre for Health Policy and Evaluation; 1998.

6. Armstrong W. The consumer experience with cataract surgery and private clinics in Alberta: Canada's canary in the mine shaft. Edmonton: Alberta Chapter of Consumers Association of Canada; 2000.

7. Davis K, Stremikis K, Squires D, et al. Mirror, mirror on the wall: how the performance of the US health care system compares internationally. New York: Commonwealth Fund; 2014.

8. Fréchette D, Hollenberg D, Shrichand A, et al. What's really behind Canada's unemployed specialists? Too many, too few doctors? Findings from the Royal College's employment study. Ottawa: Royal College of Physicians and Surgeons of Canada; 2013.

9. Lahey W. Medicare and the law: contours of an evolving relationship. In: Downie J, Caulfield T, Flood CM, editors. Canadian health law and policy. Toronto: Lexis Nexis Canada; 2001:1-73.

10. Mossialos E, Allin S, Davaki K. Analysing the Greek health system: a tale of fragmentation and inertia. Health Econ 2005;14 (Suppl 1):S151-68.

11. Biglaiser G, Ma CA. Moonlighting: public service and private practice. Rand J Econ 2007;38:1113-33.

12. Rickman N, McGuire A. Regulating providers' reimbursement in a mixed market for healthcare. Scott J Polit Econ 1999;46:53-71.

13. Morris S, Elliott B, Ma A, et al. Analysis of consultants' NHS and private incomes in England in 2003/4. J R Soc Med 2008; 101:372-80.

14. Purcell J. Medical consultants' contract. Dublin: Office of the Comptroller and Auditor General; 2007.
15. González P. Should physicians' dual practice be limited? An incentive approach. Health Econ 2004;13:505-24.

16. Oliveira MD, Pinto CG. Health care reform in Portugal: an evaluation of the NHS experience. Health Econ 2005;14(Suppl 1):S203-20

17. Lo Scalzo A, Donatini A, Orzella L, et al. Italy: health system review. Health Systems in Transition 2009;11:1-216.

18. Ferrinho P, Lerberghe WV, Fronteira I, et al. Dual practice in the health sector: review of the evidence. Hum Resour Health 2004;2:14.

19. Oliver A. The English National Health Service: 1979-2005. Health Econ 2005; 14(Suppl 1):S75-99.

20. CMA Code of Ethics (update 2004). Ottawa: Canadian Medical Association; 2004. Available: http://policybase.cma.ca/dbtw -wpd/PolicyPDF/PD04-06.pdf (accessed 2014 Dec. 3).

21. Colombo R, Tapay N. Private health insurance in OECD countries: the benefits and costs for individuals and health systems. Paris: Organisation for Economic Co-operation and Development; 2004.

22. Physician services benefit rates report. Ottawa: Canadian Institute for Health Information; 2014.

23. Hargreaves S. Government makes U turn on private practice ban. BMJ 2002;324:1473.

24. Allen v. Her Majesty the Queen, 2014 ABQB 184.

25. Terms and conditions - consultants (England) 2003. London (UK): National Health Service. Available: www.nhsemployers .org/your-workforce/pay-and-reward/nhs-terms-and-conditions /consultants-and-dental-consultants/consultant-contract-(2003) (accessed 2014 Dec. 3).

Affiliations: Faculty of Law (Flood, Thomas), University of Ottawa, Ottawa, Ont.; Department of Health Services Research and Policy (Allen), London School of Hygiene \& Tropical Medicine, London, UK; Faculty of Law (Walker), University of Toronto, Toronto, Ont.

Contributors: This article reflects preliminary findings of a research project conceived by Colleen Flood and Pauline Allen. Kathryn Walker and Bryan Thomas conducted the literature review with input from the other authors. All of the authors contributed to the drafting and revising of the manuscript, approved the final version submitted for publication and agreed to act as guarantors of the work.

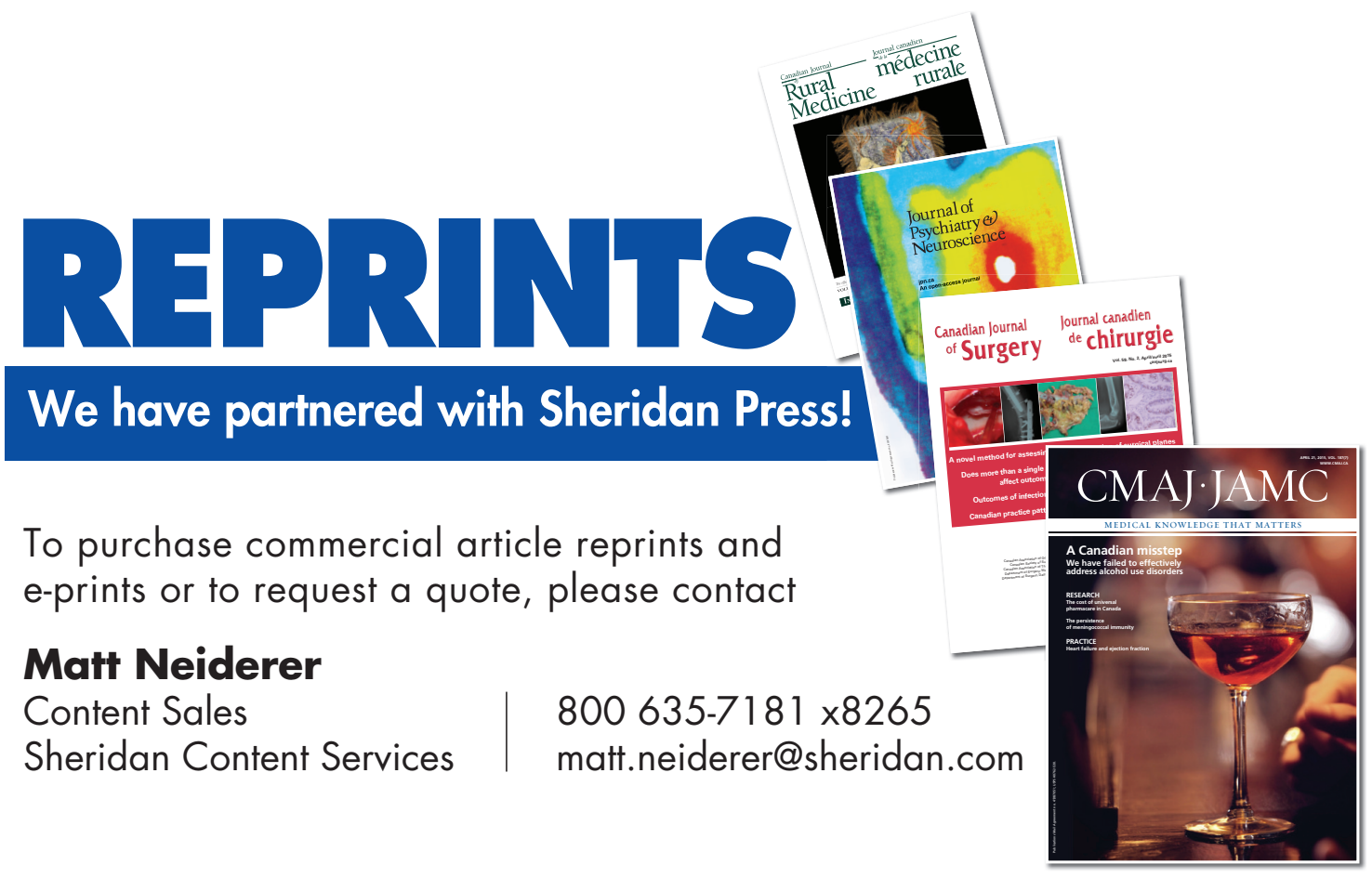

